\title{
Prevalence, Cognitive Characteristics and Influence Factors of Amnestic Mild Cognitive Impairment among Community-dwelling Older Adults in Chengdu, China
}

\section{Peiyuan Qiu}

Department of Epidemiology and Statistics, West China School of Public Health and West China Fourth Hospital, Sichuan University, Chengdu

\section{Yan Cai}

Department of Health Behavior and Social Medicine, West China School of Public Health and West China Fourth Hospital, Sichuan University, Chengdu

\section{Yangyang Wang}

Department of Epidemiology and Statistics, West China School of Public Health and West China Fourth Hospital, Sichuan University, Chengdu

\section{Shiyi Liao}

Department of Epidemiology and Statistics, West China School of Public Health and West China Fourth Hospital, Sichuan University, Chengdu

\section{Yunbo Nie}

School of Medicine and Dentistry, University of Rochester, New York

\section{Ye Wang}

Department of Psychiatry and National Clinical Research Center for Geriatrics, West China Hospital, Sichuan University, Chengdu

\section{Shan Rao}

Chengdu Jinxin Mental Diseases Hospital, Chengdu

\section{Weihong Kuang ( $\sim$ kwhhlj@scu.edu.cn )}

Department of Psychiatry and National Clinical Research Center for Geriatrics, West China Hospital, Sichuan University, Chengdu

\section{Research Article}

Keywords: Chinese, amnestic mild cognitive impairment, prevalence, neurocognitive function, risk factors

Posted Date: January 22nd, 2021

DOl: https://doi.org/10.21203/rs.3.rs-144936/v1 
License: (c) (i) This work is licensed under a Creative Commons Attribution 4.0 International License. Read Full License 


\section{Abstract}

Background: Dementia is a global public health priority. Mild cognitive impairment ( $\mathrm{MCl})$ is a transitional stage between normal aging and dementia. And amnestic $\mathrm{MCl}(\mathrm{aMCl})$ is proved to have a higher probability to develop into $A D$ comparing to other type of $\mathrm{MCl}$. Yet a few studies have focused on prevalence of $\mathrm{aMCl}$ in China. This study aims to explore the prevalence of amnestic mild cognitive impairment (aMCl), cognitive characteristics of aMCl, and associated risk factors for aMCl.

Methods: A cross-sectional study was conducted in the communities of Chengdu, China. Participants were 368 older adults aged 60 years and over. Participants completed various neuropsychological assessments, including the Mini-Mental State Examination (MMSE), the Clinical Dementia Rating (CDR), Auditory Verbal Learning Test (AVLT), Wechsler's Logical Memory Task (LMT), Boston Naming Test (BNT) and Trail Making Test Part A (TMT-A). Social information was collected by standard questionnaire. Multiple logistic regression analysis was utilized to screen for the risk and protective factors of aMCl.

Results: Data included 309 subjects with normal cognitive function and 59 with aMCl. The prevalence of aMCl was $16.0 \%$.The average age of participants was $69.06 \pm 7.30$ years, with $56.0 \%$ being females. After controlling for age, gender and education, the Spearman partial correlation coefficient between diverse cognitive assessments and $\mathrm{aMCl}$ ranged from -0.52 for the long-term delayed recall scores in AVLT to 0.19 for the time-usage scores in TMT-A, and results revealed that all domains except naming scores (after semantic cue of BNT) and error quantity (in TMT-A) showed statistically significant associations with aMCl. And the results of multiple logistic regression analysis indicated that older age $(O R=1.044$, $95 \%$ Cl: 1.002 1.087, $p=0.042)$, lower educational level, and diabetes ( $O R=2.450,95 \%$ Cl: 1.246 4.818, $p=0.009$ ) were risk factors of $\mathrm{aMCl}$.

Conclusions: Participants with aMCl showed lower cognitive function in memory, language and executive domains, especially in long-term delayed recall. The participants who were older, had less education, or with diabetes had higher risk of suffering from aMCl. These results may help clinical practitioners design and conduct targeted cognitive training and chronic disease management for the elderly, aiming to prevent and delay development of Alzheimer's dementia.

\section{Background}

Alzheimer's Disease (AD) is an increasing public health challenge, causing huge disease burdens for families, health-care systems, and societies as a whole. Currently, there is an estimated $40-50$ million people living with dementia [1, 2]. With ageing populations worldwide, this number is projected to increase to 131.5 million by 2050 [1]. Although a large amount of money has been put in developing pharmaceutical treatments for $A D$, no definitive cure current exists. However, there is growing evidence showing interventions, including pharmaceutical and non-pharmaceutical interventions [3, 4], at an earlier stage would be more likely to delay the onset and progress of $A D$. If the onset of $A D$ dementia were to be 
delayed by 5 years, it would result in a $57 \%$ reduction in the number of patients with AD, and save 344 billion to 627 billion US dollars[5].

Mild cognitive impairment $(\mathrm{MCl})$ refers to an impairment in cognition that is greater than normally expected, but has not yet significantly impaired daily function. Many studies have revealed that $\mathrm{MCls}$ are associated with increased risk of progression to $A D$ [6-8]. A review using data collected by the National Alzheimer Coordinating Center in the U.S. found that about $15.8 \%$ of $\mathrm{MCl}$ progressed to $\mathrm{AD}$ with a mean follow-up time of 2.46 years[7]. Glynn found that approximately $32 \%$ of people diagnosed with $\mathrm{MCI}$ progressed to $A D$, with a median time of 2 years[6]. Vos's study in Netherlands found that annual conversion rate from $\mathrm{MCl}$ to $\mathrm{AD}$ was $16.7 \%[8]$. In China, the reported annually conversion rate ranged from $6 \%-22 \%[9,10]$. The discrepancies in conversion rates may be due to the different study settings and heterogeneous definitions of $\mathrm{MCl}$.

However, not all people with $\mathrm{MCl}$ will develop $\mathrm{AD}$ dementia, urging scientists to study clinical subtypes of $\mathrm{MCl}$. Depending on whether memory is affected, $\mathrm{MCl}$ can be classified into two clinical subtypes: amnestic $\mathrm{MCl}(\mathrm{aMCl})$, where the memory domain is primarily involved, and non-amnestic $\mathrm{MCl}(\mathrm{naMCl})$, where the memory of the subject is not impaired. This could further be divided into single domain aMCl, multiple-domain aMCl, single domain naMCl, and multiple-domain naMCl- based on the number of cognitive domains that are impaired [11]. Increasing evidence show that people with aMCl have a higher probability to develop into $A D$ comparing to non-amnestic $\mathrm{MCl}$ [12]. A community-based longitudinal study in rural Japan found that the rate of conversion of aMCl patients to dementia was $33.3 \%$, which is higher than that among naMCl patients (17.7\%) [13]. Glynn's study showed that those with $\mathrm{aMCl}$ are nearly twice as likely to progress to $A D$ than those with naMCI [6]. Therefore, intervention on the progression associated $\mathrm{aMCl}$ is critical in terms of delaying $\mathrm{AD}$ development.

In the United States, Michau's study found an incidence of $12.4 \%$ for aMCl using data from the Uniform Data Set (UDS) of the National Alzheimer's Coordinating Center (NACC) [7]. In Australia, Pusswald found that the incidence was $15.4 \%$ for aMCl in the memory outpatient clinic [14]. A Swedish study by Overton showed that the prevalence of aMCl was 7.34\% among older adults aged 60 years old and above [15]. In addition, researchers made efforts to identify associated factors for $\mathrm{aMCl}$, and age and education were identified as important risk factors [16-18]. The results of other potential associated factors, including hypertension, diabetes, depression, sleep disturbance, physical exercise, smoking, and drinking, were not shown to be consistent $[17,19,20]$.

China is experiencing a rapid growth of its elderly population. AD dementia has become a big public health challenge and will become a huge disease burden in the coming decades. As there is currently no definitive cure for $A D$, we must prioritize the prevention of $A D$, including delaying its onset and progression. Given that $\mathrm{aMCl}$ is closely related to $\mathrm{AD}$, determining the prevalence and associated risk factors of aMCl is essential when developing preventive approaches towards AD. Three studies reported the prevalence of aMCl in China, which were $12.2 \%, 16.11 \%$ and $17.1 \%[21-23]$. The reported associated factors for $\mathrm{aMCl}$ were not consistent as reported in other countries. Due to the inconsistent conclusions 
and regional differences in previous research, we performed a study among community dwelling older adults aged 60 years old and above in Chengdu, Sichuan Province, where no related studies have been done yet. In our project, we aim to explore the prevalence of aMCl, the cognitive characteristics of aMCl, and the associated risk factors for $\mathrm{aMCl}$ within our population of focus.

\section{Methods}

\section{Study design and participants}

A sample of urban older adults was obtained from a cross-sectional survey. The survey was conducted in Jinjiang District, one of the twelve districts in Chengdu, Sichuan Province in China. Chengdu is an important central city in western China, ranking eighth in Gross Domestic Product (GDP) among all cities in China, generating 1,217.02 billion yuan in 2016. Jinjiang District also belongs to one of the central districts of Chengdu, ranking fifth in GDP (among all districts in China) with 83.46 billion yuan in 2016. In this area, $21.62 \%$ of people were aged 60 years and over in 2016 . A multi-stage cluster sampling method was applied to ensure that study participants were selected from various socio-economic sectors, which made it more representative of the population. The eleven towns in Jinjiang District were divided into three levels based on income level - low, middle, and high. Six residential areas were selected randomly from each group, with a total of 18 residential areas. Then we randomly selected three to six buildings from each residential area and investigated all older adults meeting the inclusion criteria. The data was collected from October 2016 to March 2017.

The inclusion criteria for participants were as below: 1) Permanent residents (length of residence $\geq 12$ months); and 2) 60 years old and over. Participants were excluded if they: 1) Were unable to complete the survey because of severe visual or hearing impairments, serious physical illness or weakness; 2) Had a history of traumatic brain injuries or psychiatric illnesses that affect cognitive function; 3) Might have major depressive disorders, which was defined as the Chinese self-reported version geriatric depression inventory (GDI-SR) score $\geq 3$ [24]; and 3) Were demented or had $\mathrm{MCl}$ without memory impairment. In total, 617 randomly selected older adults participated this survey. Among the selected, 13 participants had visual or hearing impairments, 20 refused to answer questions, 84 participants had symptoms of depression, 39 participants gave incomplete data, and 93 participants did not meet the diagnosis of aMCl or normal cognitive function. All in all, 368 older adults were included for analysis.

The survey protocol (including the informed consent) was approved by the Medical Ethics Committee of Sichuan University. All the participants signed the informed consent forms. Qualified research assistants with medical backgrounds and community physicians administered this survey. All the research assistants and clinicians were intensively trained by psychiatrists from the Mental Health Center of West China Hospital.

\section{Cognitive Assessment}


All participants completed the following neuropsychological assessments: Mini-Mental State Examination (MMSE), the Clinical Dementia Rating (CDR), Auditory Verbal Learning Test (AVLT), Wechsler's Logical Memory Task (LMT), Boston Naming Test (BNT) and Trail Making Test Part A (TMTA).

The MMSE scale was used to assess global cognitive function [25]. The MMSE consists of multiple questions and covers six cognitive domains: orientation (10 points), immediate memory (3 points), attention and calculation (5 points), recall ability (3 points), language (8 points), and visuospatial ability (1 point). Usually, the visuospatial ability task was classified as one of the language items. The score totals ranged from 0 to 30 , with higher scores indicating better cognitive function.

The CDR is a reliable tool for staging dementia severity [26]. It includes six cognitive categories: memory, orientation, judgment and problem solving, community affairs, home and hobbies, and personal care. According to clinical scoring rules, CDR $0=$ no dementia, CDR $0.5=$ indicates questionable dementia, CDR 1 = mild dementia, $\mathrm{CDR} 2$ = moderate dementia and CDR 3 = severe dementia. In our current study, $\mathrm{CDR}$ was also used to obtain information on cognitive complaints and activities of daily living. And the psychiatrists from Mental Health Center of West China Hospital were responsible for CDR rating.

AVLT is a well-recognized measure for verbal learning and memoryB[27]. The examiner read a list of 12 unrelated Chinese words aloud three times. Immediately following each presentation and 20 minutes after the last, the participant was required to recall as many words as possible without a time limit and in any order. The immediate recall scores consisted of the number of words recalled in each trial (range 012) and the total number of words recalled in the 3 immediate trials (range 0-36). The delayed score consisted of the number of words recalled after the 20-min delay (range 0-12), which we refer to as the long-term delayed recall in our study. In the end, the participants were shown the word list.

LMT primarily tested participants' logical memory [28]. The participants were told a short story orally, which contained 20 underlining keywords. Then the examinee was asked to recall the story (immediate recall). Approximately 20 or 30 minutes later, free recall of the story was again elicited (delayed recall).

BNT was used as a test for language assessment [29]. The theme of 30 images were asked to be named. If a participant named the item correctly, credits were given for self-corrections and it was recorded among 'spontaneous naming scores $(\mathrm{SN})$ '. If a participant gave a wrong response or gave no response within 20 seconds, the examiner provided a standard semantic cue. If a participant gave the correct answer with the cue, credit was given and was recorded under 'naming scores after phonemic cue (CN)'.

TMT-A was used to assess the execution function of participants [30]. It required the participants to link numbers from 1 to 25 as fast as possible while keeping the nib on the page. The amount of time consumed and the number of errors made were recorded, defined as TMT-A(s) and TMT-A error, respectively. 


\section{Social Information}

Social information was gathered through participants or their appropriate informants. The following data was collected by standard questionnaire: 1) Demographic data such as age, gender, educational level, marital status and income (average monthly income per person in family); 2) History of chronic diseases including hypertension, diabetes, coronary heart disease and cerebrovascular disease; 3) Daily living information (sleep disorders, smoking and drinking alcohol). Specifically, marital status consisted of two categories: "marriage" and "no marriage". The latter was defined as being divorced, widowed, or unmarried.

Sleep disorders of older adults were assessed by the Chinese version of Pittsburgh Sleep Quality Index scale (PSQI) [31], which is in the reference period of "past one month". The scale contains 19 items scored on a 3-point Likert scale and can be divided to 7 domains: subjective sleep quality, sleep latency, sleep duration, sleep efficiency, sleep disturbances, use of sleep medications and daytime dysfunction. The global PSQI scores ranged from 0 to 21, with higher total scores indicating worse sleep quality. The Chinese version of the PSQI has been confirmed to show good reliability and validity [32].

\section{Diagnostic Criteria}

Diagnosis of aMCl was made based on Petersen's criteria [33-35] : 1) Memory complaint by participants, preferably corroborated by their informants; 2) Objective memory impairment in addition to a $z$ score $\leq$ -1.5 for at least one memory neuropsychological test and a CDR score of $0.5 ; 3$ ) Preserved general cognitive function according to MMSE scores adjusted by educational level [36] (>17 for illiterate, $>20$ for primary school and $>24$ for above the middle school); 4) Intact daily living ability; and 5) Absence of dementia. Ultimately, among 368 older adults in this study, 59 were aMCl participants and 309 were participants with normal cognitive function.

\section{Statistical Analysis}

The continuous variable was presented as mean \pm standard deviation (SD) and categorical variables were described in terms of frequency (\%). The Spearman correlation coefficient and the Spearman partial correlation coefficient controlling age, gender and educational level were used to detect differences in cognitive test results between the aMCl group and normal group (individuals in the aMCl group were assigned a value of 1 and individuals in the normal group were assigned a value of 0 ). A comparison of continuous data among aMCl participants and those with normal cognitive function was performed using independent-sample t-test analysis. Chi-square tests were applied to examine group differences in dichotomous variables data. For the ordinal categorical variable (educational level), the CochranArmitage test for trend was used to verify whether the prevalence of aMCl is higher with the lower educational level. Multiple logistic regression analysis was utilized to screen for the risk and protective 
factors of aMCl. The reported $p$ values are the results of two-sided tests. $P$ values of $<0.05$ were considered as statistically significant. Statistical analysis was performed using Stata version 15.1.

\section{Results}

\section{Prevalence and Cognitive Characteristics}

In this study, the prevalence of aMCI was $16.0 \%$. Comparison of cognitive characteristics between participants with $\mathrm{aMCl}$ and participants with normal cognitive function summarized in Table 1 . The unadjusted Spearman correlation coefficients ranged from -0.58 for the AVLT-LR to 0.26 for the TMT-A (s). The results revealed that the scores of participants with aMCl on MMSE, AVLT, LMT and spontaneous naming scores (BNT) were lower than those of cognitively normal participants $(p<0.05)$, and the patients with aMCl consumed longer time and made more errors in TMT-A compared to the normal group $(p<$ 0.05 ). When controlling age, gender and educational level, the Spearman partial correlation coefficient ranged from -0.52 for the AVLT-LR to 0.19 for the TMT-A (s). The participants in aMCl group also performed worse in most cognitive assessments compared to those in the normal group $(p<0.05)$. While there were no significant differences between groups in naming scores after semantic cue of BNT based on unadjusted or adjusted correlational analysis, we also did not see significant differences in TMT-A error after adjusting for age, gender and education. Using a $z$ score $\leq-1.5$ for each neuropsychological test, there were 29 (49.2\%) aMCl participants with only memory impairment, $13(22.0 \%)$ with memory and language (BNT) impairment, 12 (20.3\%) with memory and executive function (TMT-A) impairments, and 5 $(8.5 \%)$ with memory, language (BNT) and executive function (TMT-A) impairments among participants with aMCl. 
Table 1

Cognitive assessment scores in participants with aMCl and normal group

\begin{tabular}{|c|c|c|c|c|c|c|c|}
\hline $\begin{array}{l}\text { Cognitive } \\
\text { assessments }\end{array}$ & $\begin{array}{l}\text { Total } \\
(n=368)\end{array}$ & $\begin{array}{l}\text { aMCl } \\
(n=59)\end{array}$ & $\begin{array}{l}\text { Normal } \\
(n=309)\end{array}$ & $\begin{array}{l}\text { Spearman } \\
\rho\end{array}$ & $p$ & $\begin{array}{l}\text { Spearman } \\
\rho^{*}\end{array}$ & $p$ \\
\hline MMSE & $\begin{array}{l}26.56 \pm \\
2.47\end{array}$ & $\begin{array}{l}24.17 \pm \\
2.98\end{array}$ & $\begin{array}{l}27.02 \pm \\
2.07\end{array}$ & -0.36 & $<0.001$ & -0.29 & $\dot{0.001}$ \\
\hline \multicolumn{8}{|l|}{ AVLT } \\
\hline AVLT-1 & $\begin{array}{l}2.93 \pm \\
1.66\end{array}$ & $\begin{array}{l}1.85 \pm \\
1.14\end{array}$ & $\begin{array}{l}3.14 \pm \\
1.66\end{array}$ & -0.28 & $<0.001$ & -0.21 & $\begin{array}{l}<.001 \\
0.001\end{array}$ \\
\hline AVLT-2 & $\begin{array}{l}5.12 \pm \\
2.16\end{array}$ & $\begin{array}{l}3.12 \pm \\
1.49\end{array}$ & $\begin{array}{l}5.50 \pm \\
2.05\end{array}$ & -0.41 & $<.001$ & -0.33 & $\hat{0}_{0.001}$ \\
\hline AVLT-3 & $\begin{array}{l}6.28 \pm \\
2.67\end{array}$ & $\begin{array}{l}3.66 \pm \\
1.61\end{array}$ & $\begin{array}{l}6.78 \pm \\
2.54\end{array}$ & -0.44 & $<.001$ & -0.37 & $\begin{array}{l}< \\
0.001\end{array}$ \\
\hline AVLT-sum 1-3 & $\begin{array}{l}14.33 \pm \\
5.66\end{array}$ & $\begin{array}{l}8.63 \pm \\
3.20\end{array}$ & $\begin{array}{l}15.42 \pm \\
5.36\end{array}$ & -0.46 & $\begin{array}{l}<.001 \\
0.0\end{array}$ & -0.37 & $\dot{0.001}$ \\
\hline AVLT-LR & $\begin{array}{l}5.06 \pm \\
2.92\end{array}$ & $\begin{array}{l}1.19 \pm \\
0.92\end{array}$ & $\begin{array}{l}5.80 \pm \\
2.56\end{array}$ & -0.58 & $<001$ & -0.52 & $\dot{<} 001$ \\
\hline \multicolumn{8}{|l|}{ LMT } \\
\hline LMT-IR & $\begin{array}{l}5.14 \pm \\
3.22\end{array}$ & $\begin{array}{l}2.97 \pm \\
2.89\end{array}$ & $\begin{array}{l}5.55 \pm \\
3.11\end{array}$ & -0.31 & $<.001$ & -0.19 & $\dot{0.001}$ \\
\hline LMT-DR & $\begin{array}{l}4.52 \pm \\
3.28\end{array}$ & $\begin{array}{l}2.49 \pm \\
3.09\end{array}$ & $\begin{array}{l}4.90 \pm \\
3.18\end{array}$ & -0.29 & $\begin{array}{l}<.001 \\
0.00\end{array}$ & -0.19 & $\begin{array}{l}<.001 \\
0.001\end{array}$ \\
\hline \multicolumn{8}{|l|}{ BNT } \\
\hline BNT-SN & $\begin{array}{l}19.47 \pm \\
4.35\end{array}$ & $\begin{array}{l}16.02 \pm \\
4.54\end{array}$ & $\begin{array}{l}20.13 \pm \\
3.99\end{array}$ & -0.32 & $\begin{array}{l}< \\
0.001\end{array}$ & -0.21 & $\dot{0.001}$ \\
\hline BNT-CN & $\begin{array}{l}1.60 \pm \\
2.10\end{array}$ & $\begin{array}{l}1.64 \pm \\
1.64\end{array}$ & $\begin{array}{l}1.59 \pm \\
2.18\end{array}$ & 0.03 & 0.555 & -0.05 & 0.310 \\
\hline \multicolumn{8}{|l|}{ TMT-A } \\
\hline TMT-A (s) & $\begin{array}{l}78.46 \pm \\
41.38\end{array}$ & $\begin{array}{l}107.75 \pm \\
57.35\end{array}$ & $\begin{array}{l}72.86 \pm \\
35.00\end{array}$ & 0.26 & $<.001$ & 0.19 & $\begin{array}{l}< \\
0.001\end{array}$ \\
\hline
\end{tabular}

Abbreviations: AVLT-LR, long-term delayed recall scores of Auditory Verbal Learning Test; LMT-IR, immediate recall scores of Logical Memory Test; LMT-DR, delayed recall scores of Logical Memory Test; BNT-SN, spontaneous naming scores of Boston Naming Test; BNT-CN, naming scores after semantic cue of Boston Naming Test.

*Spearman partial correlation coefficient for the association between $\mathrm{aMCl}$ and normal group (the aMCl group was assigned a value of 1 , and the normal group was assigned a value of 0 ), controlled for age, gender, and educational level. 


\begin{tabular}{|c|c|c|c|c|c|c|c|}
\hline $\begin{array}{l}\text { Cognitive } \\
\text { assessments }\end{array}$ & $\begin{array}{l}\text { Total } \\
(n=368)\end{array}$ & $\begin{array}{l}\text { aMCl } \\
(n=59)\end{array}$ & $\begin{array}{l}\text { Normal } \\
(n=309)\end{array}$ & $\begin{array}{l}\text { Spearman } \\
\rho\end{array}$ & $p$ & $\begin{array}{l}\text { Spearman } \\
\rho^{\star}\end{array}$ & $p$ \\
\hline TMT-A error & $\begin{array}{l}0.92 \pm \\
2.26\end{array}$ & $\begin{array}{l}1.68 \pm \\
2.82\end{array}$ & $\begin{array}{l}0.78 \pm \\
2.11\end{array}$ & 0.19 & $\begin{array}{l}< \\
0.001\end{array}$ & 0.08 & 0.151 \\
\hline \multicolumn{8}{|c|}{$\begin{array}{l}\text { Abbreviations: AVLT-LR, long-term delayed recall scores of Auditory Verbal Learning Test; LMT-IR, } \\
\text { immediate recall scores of Logical Memory Test; LMT-DR, delayed recall scores of Logical Memory } \\
\text { Test; BNT-SN, spontaneous naming scores of Boston Naming Test; BNT-CN, naming scores after } \\
\text { semantic cue of Boston Naming Test. }\end{array}$} \\
\hline \multicolumn{8}{|c|}{$\begin{array}{l}\text { *Spearman partial correlation coefficient for the association between aMCl and normal group (the } \\
\text { aMCl group was assigned a value of } 1 \text {, and the normal group was assigned a value of } 0 \text { ), controlled } \\
\text { for age, gender, and educational level. }\end{array}$} \\
\hline
\end{tabular}

\section{Sociodemographic and Clinical Characteristics}

In this study, the average age of participants was $69.06 \pm 7.30$ years old. Female participants accounted for $56.0 \%$, and participants with a middle school education and above accounted for $60.3 \%$. The participants' sociodemographic and clinical characteristics were presented in Table 2. The age, prevalence of hypertension and diabetes between participants with aMCl, and normal group were statistically different $(p<0.05)$. And the results of Cochran-Armitage test for trend indicated that the prevalence of aMCl was increased with decreasing educational level $(p<0.05)$. However, participants with aMCl and participants in the normal group did not differ in gender, marital status, income, coronary heart disease, cerebrovascular disease, sleep disorders, smoking or drinking. 
Table 2

Comparison of sociodemographic and clinical characteristics between participants with $\mathrm{aMCl}$ and normal group

\begin{tabular}{|c|c|c|c|c|c|}
\hline Variables & $\begin{array}{l}\text { Total } \\
(n=368)\end{array}$ & $\begin{array}{l}\text { aMCl } \\
(n=59)\end{array}$ & $\begin{array}{l}\text { Normal } \\
(n=309)\end{array}$ & $t / \chi^{2}$ & $p$-value \\
\hline \multicolumn{6}{|l|}{ Demographic factors } \\
\hline Age (Mean $\pm S D)$ & $69.06 \pm 7.30$ & $72.97 \pm 9.06$ & $68.32 \pm 6.68$ & -4.60 & $<0.001$ \\
\hline Gender (\%) & & & & 0.32 & 0.572 \\
\hline Male & $162(44.0)$ & $24(14.8)$ & $138(85.2)$ & & \\
\hline Female & $206(56.0)$ & $35(17.0)$ & $171(83.0)$ & & \\
\hline Education (\%) & & & & 40.96 & $<0.001$ \\
\hline Above middle school & $222(60.3)$ & $16(7.2)$ & $206(92.8)$ & & \\
\hline Primary school & $102(27.7)$ & $24(23.5)$ & 78 (76.5) & & \\
\hline Illiteracy & $44(12.0)$ & $19(43.2)$ & $25(56.8)$ & & \\
\hline Marital status (\%) & & & & 2.46 & 0.117 \\
\hline Marriage & 301 (81.8) & $44(14.6)$ & $257(85.4)$ & & \\
\hline No marriage & $67(18.2)$ & $15(22.4)$ & $52(77.6)$ & & \\
\hline Income (\%) & & & & 0.02 & 0.882 \\
\hline$>3000$ yuan & 109 (29.6) & $17(15.6)$ & $92(84.4)$ & & \\
\hline$\leq 3000$ yuan & $259(70.4)$ & $42(16.2)$ & $217(83.8)$ & & \\
\hline \multicolumn{6}{|l|}{ Chronic diseases } \\
\hline Hypertension (\%) & & & & 8.54 & 0.003 \\
\hline No & $195(53.0)$ & $21(10.8)$ & $174(89.2)$ & & \\
\hline Yes & $173(47.0)$ & $38(22.0)$ & $135(78.0)$ & & \\
\hline Diabetes (\%) & & & & 10.43 & 0.001 \\
\hline No & $289(78.5)$ & $37(12.8)$ & $252(87.2)$ & & \\
\hline Yes & 79 (21.5) & $22(27.9)$ & $57(72.1)$ & & \\
\hline Coronary heart disease (\%) & & & & 0.18 & 0.672 \\
\hline No & 330 (89.7) & $52(15.8)$ & 278 (84.2) & & \\
\hline
\end{tabular}

Abbreviations: SD, standard deviation. 


\begin{tabular}{|llllll|}
\hline Variables & $\begin{array}{l}\text { Total } \\
(\boldsymbol{n = 3 6 8 )}\end{array}$ & $\begin{array}{l}\text { aMCI } \\
(\boldsymbol{n}=59)\end{array}$ & $\begin{array}{l}\text { Normal } \\
(\boldsymbol{n}=309)\end{array}$ & t/ $\chi^{2}$ & $p$-value \\
\hline Yes & $38(10.3)$ & $7(18.4)$ & $31(81.6)$ & & \\
\hline Cerebrovascular disease (\%) & & & & 2.38 & 0.123 \\
\hline No & $332(90.2)$ & $50(15.1)$ & $282(84.9)$ & & \\
\hline Yes & $36(9.8)$ & $9(25.0)$ & $27(75.0)$ & & \\
\hline Daily living information & & & & & \\
\hline Sleep disorders (Mean \pm SD) & $6.07 \pm 4.23$ & $6.41 \pm 4.45$ & $6.01 \pm 4.19$ & -0.66 & 0.509 \\
\hline Smoking (\%) & & & & 2.55 & 0.110 \\
\hline No & $304(82.6)$ & $53(17.4)$ & $251(82.6)$ & & \\
\hline Yes & $64(17.4)$ & $6(9.4)$ & $58(90.6)$ & & \\
\hline Drinking (\%) & & & & & \\
\hline No & $141(38.3)$ & $18(12.8)$ & $123(87.2)$ & & \\
\hline Yes & $227(61.7)$ & $41(18.1)$ & $186(81.9)$ & & \\
\hline Abbreviations: SD, standard deviation. & & & & \\
\hline
\end{tabular}

\section{Risk factors}

In the multiple logistic regression analysis, our model included sociodemographic and clinical characteristics that were statistically associated with the prevalence of aMCl. As such, age, educational level, hypertension, and diabetes were selected. Considered as a confounder, gender was also placed in the model. The results shown in Table 3 demonstrate that older age $(O R=1.044,95 \% \mathrm{Cl}: 1.002 \sim 1.087, p$ $=0.042)$, obtaining less education, and having diabetes $(O R=2.450,95 \% \mathrm{Cl}: 1.246 \sim 4.818, p=0.009)$ were risk factors of aMCl. Particularly, the risk of aMCl among the illiterate $(O R=8.161,95 \%$ Cl. $3.402 \sim$ $19.575, p<0.001)$ was nearly twice as high compared to those with primary school education $(O R=$ $3.746,95 \% \mathrm{Cl}: 1.816 \sim 7.724, p<0.001)$, using participants with middle school education or above as a baseline ( $95 \% \mathrm{Cl}$ of 1.000$)$. However, no statistical association with the prevalence of aMCl was seen with gender and hypertension $(p>0.05)$. 
Table 3

Multiple logistic regression analysis of risk factors for $\mathrm{aMCl}$

\begin{tabular}{|lllllll|}
\hline Variables & $\boldsymbol{B}$ & SE & Wald score & p-value & OR & $95 \% \mathrm{Cl}$ \\
\hline Age & 0.043 & 0.021 & 2.040 & 0.042 & 1.044 & $1.002 \sim 1.087$ \\
\hline Gender & & & & & & \\
\hline Male & - & - & - & - & - & 1.000 \\
\hline Female & -0.252 & 0.330 & -0.760 & 0.445 & 0.777 & $0.407 \sim 1.485$ \\
\hline Education level & & & & & & \\
\hline Above middle school & - & - & - & - & - & 1.000 \\
\hline Primary school & 1.321 & 0.369 & 3.580 & $<0.001$ & 3.746 & $1.816 \sim 7.724$ \\
\hline Illiteracy & 2.099 & 0.446 & 4.700 & $<0.001$ & 8.161 & $3.402 \sim 19.575$ \\
\hline Hypertension & & & & & & \\
\hline No & - & - & - & - & - & 1.000 \\
\hline Yes & 0.573 & 0.324 & 1.770 & 0.077 & 1.773 & $0.940 \sim 3.343$ \\
\hline Diabetes & & & & & & \\
\hline No & - & - & - & - & - & 1.000 \\
\hline Yes & 0.896 & 0.345 & 2.600 & 0.009 & 2.450 & $1.246 \sim 4.818$ \\
\hline Abbreviations: SE, Standard Error; OR, Odds Ratio; Cl, Confidence Interval. & \\
\hline
\end{tabular}

\section{Discussion}

To the best of our knowledge, this is the first study in Western China focusing on the prevalence and characteristics of aMCl and its associated factors among older adults in the community aged 60 years and over. We found that the prevalence of aMCl among older adults in community-dwellings in Chengdu was $16.0 \%$, which is similar to the prevalence found by $\mathrm{Li}$ (the prevalence of $17.1 \%$ for aMCl among the older adults aged 60 years old and above) [21], and Zhang (the prevalence of $16.1 \%$ for aMCl among older adults in Shijiazhuang) [23] in China. The reported prevalence rates of aMCl in many other countries were between $7.3 \%-11.6 \%$, which were lower than that in China, including our study $[15,18,37,38]$. One explanation is that different survey scales, sample size, and sampling methods might impact the prevalence rates within different cultural contexts. Another potential explanation is that early life experiences can drastically influence cognitive health in later in life. Our participants were born before 1957, meaning they may have experienced the Great Famine in the early 1960s, which led to malnutrition while growing up. To further amplify these trends, they may have experienced the Cultural Revolution, 
during which education was discouraged. Education is an important protective factor against cognitive decline.

After adjusting for age, gender and education, we found that almost all global cognitive function and individual neuropsychological domains were statistically different between those with normal cognitive function and those with aMCl, except for the semantic cue naming of Boston Naming Test (BNT language) scores and the number of errors in Trail Making Test Part A (executive function). Compared to other domains, verbal learning and recall showed stronger relationships with $\mathrm{aMCl}$, of which delayed recall showed the strongest association. This finding is in line with previous studies. Zhao's study found that both short-term delay and long-term delay had the same value in identifying aMCl patients [39]. Fisher's and Simon's study suggested that delayed recall had a higher predictive value for conversion of aMCI to $A D$ compared to other domains of cognitive test $[40,41]$. The evidence suggested that the default mode network (DMN), including the posterior cingulate cortex (PCC), medial prefrontal cortex (MPFC), the medial temporal lobe, and the inferior parietal cortex, plays an important role in the encoding and retrieval of plot memory [42-44]. And in people living with mild AD, one of the most prominent characteristics is having problematic connectivity in the DMN[45]. For example, Weiler found that DMN connectivity was related to delayed recall, supporting the hypothesis that DMN plays an important role in episodic memory performance [45].

In our study, we found that increasing age was associated with increased prevalence of aMCl. Age is also the most important factor for AD, with older age being associated with higher rates of AD. In China, a systematic review in 2010 showed that the prevalence of $A D$ was $1.27 \%$ at age 65 to 69 years and $18.54 \%$ at age 85 to 89 years0[46]. The 2020 Alzheimer's Disease Facts and Figures reported that in the United States, the percentage of people with $A D$ increases greatly with age: $3 \%$ of people age $65-74,17 \%$ of people age $75-84$ and $32 \%$ of people age 85 or older have AD [47]. Similar results were found worldwide. aMCl is a subtype of $\mathrm{MCl}$, is characterized by memory impairment and highly associated with developing into $A D$. The results of the association between age and prevalence rates of aMCl in different countries are mixed. Many studies reported that age was a risk factor for aMCI $[7,15,16]$. However, Sosa's study in Latin America, China, and India showed while positive relationships between age and aMCl prevalence were seen in some of the countries, others had negative associations [48]. However, age is consistently a risk factor for conversion from $\mathrm{aMCl} / \mathrm{MCl}$ to $\mathrm{AD}$ [49]. It is worth noticing that $\mathrm{aMCl}$ is not a normal part of aging, and older age alone is not sufficient to cause aMCl.

A second finding was that education was a protective factor for $\mathrm{aMCl}$. This is consistent with previous studies indicating that increasing education is negatively related to $\mathrm{aMCl}, \mathrm{MCl}, A D$, and is also protective against the development of $\operatorname{AD}[22,50,51]$. This could be explained by the Cognitive Reserve Hypothesis. To highlight this point, research has shown that having a higher cognitive reserve, which refers to the brain's ability to make flexible and efficient use of cognitive networks (networks of neuron-to-neuron connections), helps a person's ability to cope and compensate for brain damage [47, 52]. Therefore, it is reasonable that having a higher education level can delay the progression of cognitive impairment and AD by way of increasing one's cognitive reserve. 
We found that diabetes was a risk factor for $\mathrm{aMCl}$, which is consistent with previous studies. Both crosssectional and longitudinal studies have demonstrated the effect of diabetes in modulating the risk of cognitive impairment[53-55]. However, the underlying mechanism of how diabetes impairs cognitive function is still unclear. One theory is that cerebral insulin resistance promotes tau protein phosphorylation, which facilitates the brain's susceptibility to neurodegeneration, which in turn may lead to $A D$ disease[56]. Another emerging concept in mechanistic studies is the potential role of advanced glycation end products (AGEs). AGEs increase the production of reactive oxygen species, which promote oxidative stress and inflammatory cytokines, leading to diabetes-associated neurovascular damage[57]. Moreover, diabetes is also associated with abnormalities such as accelerated hippocampal atrophy and decreases in whole brain volume, leading to neurodegeneration[54].

We did not observe an association between hypertension and $\mathrm{aMCl}$ after adjusting for demographic factors. Some studies have shown that hypertension was associated with cognitive impairment and dementia [58,59], however, there is no clear answer on the effects of hypertension on the subtypes of mild cognitive impairment. Casado's study observed that hypertension was associated with aMCl [60], while others found arelationship with naMCl, especially with vascular dementia $(\operatorname{VaD})[18,58]$. Moreover, the evidence showed that $\mathrm{aMCl}$ had a greater tendency to develop into $\mathrm{AD}$, while naMCI was more likely to develop into $\operatorname{VaD}[12,19]$. In our study, we did not observe an association bewteen aMCl and cardiocerebrovascular diseases, smoking, and drinking, which may indicate that cardio-cerebrovascular related diseases and risk factors are not related to $\mathrm{aMCl}$, but instead to naMCl. However, we did not have enough naMCl cases in our study to investigate if hypertension and other cardio-cerebrovascular diseases were related to naMCl. In addition, given that most current studies do not consider the severity or duration of hypertension, there is room to expand our understanding of the mechanism through which hypertension and cardio-cerebrovascular diseases impact aMCl, naMCl, VaD, and AD. This could be further explored with a well-designed cohort study.

Finally, we did not find an association between $\mathrm{aMCl}$ and sleep disorders. Although there were many studies which showed that sleep disturbance increased risk of aMCI [61-63], some studies demonstrated the opposite. Gavuoto's study in a large sample of community-dwelling older adults found that those who had less sleep disruption were more like to report higher levels of subjective memory decline, one of the diagnostic criteria for aMCl [64]. They argued that this might be due to compensatory sleep behavior in response to greater cognitive effort to maintain memory function [64]. It should be noted that the Pittsburgh Sleep Quality Index scale does not have indices of sleep depth and stages, indicating different sleep patterns. Analyzing sleep patterns will also help us to understand which kind of sleep disturbance are associated with $\mathrm{aMCl}$ and $\mathrm{AD}$. A system review foundthat patients with $\mathrm{aMCl}$ may experience more disturbances in sleep efficiency and slow wave sleep [65]. Further longitudinal analyses of cohorts will be required to fully evaluate the associations between sleep and $\mathrm{aMCl}$.

\section{Strengths And Limitations}


By dividing participants with $\mathrm{MCl}$ into its clinical subtypes, we were able to explore risk factors for amnestic mild cognitive impairment (aMCl) that had a higher probability to convert into Alzheimer's dementia (AD). These results have great implications for AD prevention. We also compared cognitive characteristics between cognitively normal participants and participants with aMCl. When implicated in clinical practice, our findings suggest clinicians need to pay more attention to patients who have verbal learning and memory problems, especially in long-term delayed recall.

We recognize several important limitations as well. First, although our sample is representative for urban settings, urban settings have a lot of difference from rural settings in terms of economic, culture, and so on. Therefore, our results should not be generalized to rural older adults. Besides, given that community samples are expected to be milder than those of clinical samples, and these results cannot be generalized to clinical samples. Second, even though we used strict criteria to identify aMCl cases, we did not have brain imaging or genetic information, both of which are important for diagnosing aMCl. Thus, the prevalence of aMCl may be slightly overestimated. Finally, this was a cross-sectional study that should not be used to generate causal relationships. To understand the dynamic processes that potentially contribute to the development of aMCl, research with longitudinal designs are needed.

\section{Conclusion}

This study found a high prevalence of aMCl in urban, community-dwelling older adults aged 60 years and over in Chengdu, China. Compared with cognitively normal persons, people living with aMCl showed lower cognitive function in memory, language, and executive domains, among which long-term delayed recall had the strongest association with $\mathrm{aMCl}$ after adjusting age, gender and education. Therefore, this study suggests that in clinical practice, clinicians should pay more attention to people who have verbal learning and memory problems, especially those with problems in long-term delayed recall. Moreover, this study shows that older age, lower education and diabetes are associated with $\mathrm{aMCl}$. The results indicate that cognitive training and chronic disease management may prevent and delay the development of Alzheimer's dementia.

\section{Abbreviations}

MCl: mild cognitive impairment; aMCl: amnestic MCl; MMSE: Mini-Mental State Examination; CDR: Clinical Dementia Rating; AVLT: Auditory Verbal Learning Test; LMT : Wechsler's Logical Memory Task; BNT: Boston Naming Test; TMT-A: Trail Making Test Part A; AD: Alzheimer's Disease; naMCl: nonamnestic MCl; UDS: Uniform Data Set; NACC: National Alzheimer's Coordinating Center; GDP: Gross Domestic Product; GDI-SR: self-reported version geriatric depression inventory; SN: spontaneous naming scores; CN: naming scores after phonemic cue; PSQI: Sleep Quality Index scale; SD: standard deviation; DMN: default mode network; PCC: posterior cingulate cortex; MPFC: medial prefrontal cortex; AGEs: advanced glycation end products.

\section{Declarations}




\section{Acknowledgments}

We thank the participants, caregivers, and study partners that contributed to this study.

\section{Author's contributions}

$P Q$ designed the study, carried it out, supervised the data collection and wrote the manuscript. YC designed the study, carried it out, analyzed the data and wrote the manuscript. YYW and SL analyzed the data and assisted with writing the article. YN assisted with writing and critical revision the article. YW and SR contributed to the design and supervised the data collection. WK was responsible for designing the study, carrying it out, supervising the data collection and analysis and revising the manuscript.

\section{Funding}

This study and authors are funded by the following funding organizations: Peiyuan Qiu is currently receiving grant CMB14-198 from the China Medical Board. Weihong Kuang is currently receiving grants 81621003 from the National Natural Science Foundation of China and Z20191006 from the National Clinical Research Center for Geriatrics, West China Hospital, Sichuan University.

\section{Availability of data and materials}

The datasets used during the current study are available from the corresponding author on reasonable request.

\section{Ethics approval and consent to participate}

This study was reviewed and approved by the Special Committee on Clinical trial and Biomedical Ethics in West China Hospital of Sichuan University. Informed consent was signed by all participants before interviews. All participants were free to ask any questions and to withdraw if they did not wish to continue. All procedures comply with the ethical standards of the relevant national and institutional committees on human experimentation.

\section{Consent for publication}

Not applicable.

\section{Conflict of interest}


None.

\section{Author details}

${ }^{1}$ Department of Epidemiology and Statistics, West China School of Public Health and West China Fourth Hospital, Sichuan University, Chengdu, China

${ }^{2}$ Department of Health Behavior and Social Medicine, West China School of Public Health and West China Fourth Hospital, Sichuan University, Chengdu, China

${ }^{3}$ School of Medicine and Dentistry, University of Rochester, New York, USA

${ }^{4}$ Department of Psychiatry and National Clinical Research Center for Geriatrics, West China Hospital, Sichuan University, Chengdu, China

${ }^{5}$ Chengdu Jinxin Mental Diseases Hospital, Chengdu, China

\section{References}

1. Prince M, Wimo A, Guerchet M, Ali GC, Wu YT, Prina M: World Alzheimer Report 2015. The Global Impact of Dementia. An Analysis of Prevalence, Incidence, Cost and Trends; 2015. p.1

2. Wu YT, Beiser AS, Breteler MMB, Fratiglioni L, Helmer C, Hendrie HC, Honda H, Ikram MA, Langa KM, Lobo $A$ et al: The changing prevalence and incidence of dementia over time - current evidence. Nat Rev Neurol 2017, 13(6):327-339.

3. Jia RX, Liang JH, Xu Y, Wang YQ: Effects of physical activity and exercise on the cognitive function of patients with Alzheimer disease: a meta-analysis. BMC Geriatr 2019, 19(1):181.

4. Liang JH, Shen WT, Li JY, Qu XY, Li J, Jia RX, Wang YQ, Wang S, Wu RK, Zhang HB et al: The optimal treatment for improving cognitive function in elder people with mild cognitive impairment incorporating Bayesian network meta-analysis and systematic review. Ageing Res Rev 2019, 51:8596.

5. Sperling RA, Aisen PS, Beckett LA, Bennett DA, Craft S, Fagan AM, Iwatsubo T, Jack CR, Jr., Kaye J, Montine TJ et al: Toward defining the preclinical stages of Alzheimer's disease: recommendations from the National Institute on Aging-Alzheimer's Association workgroups on diagnostic guidelines for Alzheimer's disease. Alzheimers Dement 2011, 7(3):280-292.

6. Glynn K, O'Callaghan M, Hannigan O, Bruce I, Gibb M, Coen R, Green E, B AL, Robinson D: Clinical utility of mild cognitive impairment subtypes and number of impaired cognitive domains at predicting progression to dementia: A 20-year retrospective study. Int J Geriatr Psychiatry 2020; 36(1):31-37

7. Michaud TL, Su D, Siahpush M, Murman DL: The Risk of Incident Mild Cognitive Impairment and Progression to Dementia Considering Mild Cognitive Impairment Subtypes. Dement Geriatr Cogn Dis 
Extra 2017, 7(1):15-29.

8. Vos SJ, Verhey F, Frolich L, Kornhuber J, Wiltfang J, Maier W, Peters O, Ruther E, Nobili F, Morbelli S et al: Prevalence and prognosis of Alzheimer's disease at the mild cognitive impairment stage. Brain 2015, 138(Pt 5):1327-1338.

9. Wang YP, Zhai JB, Zhu F, Zhang WW, Yang XJ, Qu CY: [Three-year follow-up study on the outcome of mild cognitive impairment to Alzheimer's disease in the elderly in Taiyuan community]. Chinese Journal of Epidemiology 2011(02):105-109.

10. Zheng W, Yao Z, Xie Y, Fan J, Hu B: Identification of Alzheimer's Disease and Mild Cognitive Impairment Using Networks Constructed Based on Multiple Morphological Brain Features. Biol Psychiatry Cogn Neurosci Neuroimaging 2018, 3(10):887-897.

11. Petersen RC, Morris JC: Mild cognitive impairment as a clinical entity and treatment target. Arch Neurol 2005, 62(7):1160-1163; discussion 1167.

12. Luis CA, Loewenstein DA, Acevedo A, Barker WW, Duara R: Mild cognitive impairment: directions for future research. Neurology 2003, 61(4):438-444.

13. Kida J, Nemoto K, Ikejima C, Bun S, Kakuma T, Mizukami K, Asada T: Impact of Depressive Symptoms on Conversion from Mild Cognitive Impairment Subtypes to Alzheimer's Disease: A Community-Based Longitudinal Study. J Alzheimers Dis 2016, 51(2):405-415.

14. Pusswald G, Moser D, Gleiss A, Janzek-Hawlat S, Auff E, Dal-Bianco P, Lehrner J: Prevalence of mild cognitive impairment subtypes in patients attending a memory outpatient clinic-comparison of two modes of mild cognitive impairment classification. Results of the Vienna Conversion to Dementia Study. Alzheimers Dement 2013, 9(4):366-376.

15. Overton M, Pihlsgard M, Elmstahl S: Prevalence and Incidence of Mild Cognitive Impairment across Subtypes, Age, and Sex. Dement Geriatr Cogn Disord 2019, 47(4-6):219-232.

16. Jester DJ, Andel R, Cechova K, Laczo J, Lerch O, Markova H, Nikolai T, Vyhnalek M, Hort J: Cognitive Phenotypes of Older Adults with Subjective Cognitive Decline and Amnestic Mild Cognitive Impairment: The Czech Brain Aging Study. J Int Neuropsychol Soc 2020:1-14.

17. Low LF, Brodaty H, Edwards R, Kochan N, Draper B, Trollor J, Sachdev P: The prevalence of "cognitive impairment no dementia" in community-dwelling elderly: a pilot study. Aust N Z J Psychiatry 2004, 38(9):725-731.

18. Peltz CB, Corrada MM, Berlau DJ, Kawas CH: Cognitive impairment in nondemented oldest-old: prevalence and relationship to cardiovascular risk factors. Alzheimers Dement 2012, 8(2):87-94.

19. Valenza S, Paciaroni L, Paolini S, Bonfigli AR, Di Rosa M, Rabini RA, Tortato E, Pelliccioni P, Pelliccioni G: Mild Cognitive Impairment Subtypes and Type 2 Diabetes in Elderly Subjects. J Clin Med 2020, 9(7).

20. Wang T, Xiao S, Chen K, Yang C, Dong S, Cheng Y, Li X, Wang J, Zhu M, Yang F et al: Prevalence, Incidence, Risk and Protective Factors of Amnestic Mild Cognitive Impairment in the Elderly in Shanghai. Curr Alzheimer Res 2017, 14(4):460-466. 
21. Li W, Sun L, Xiao S: Prevalence, Incidence, Influence Factors, and Cognitive Characteristics of Amnestic Mild Cognitive Impairment Among Older Adult: A 1-Year Follow-Up Study in China. Front Psychiatry 2020, 11:75.

22. Rao D, Luo X, Tang M, Shen Y, Huang R, Yu J, Ren J, Cheng X, Lin K: Prevalence of mild cognitive impairment and its subtypes in community-dwelling residents aged 65 years or older in Guangzhou, China. Arch Gerontol Geriatr 2018, 75:70-75.

23. Zhang YY, Duan JY, Zhang YX, Liang DM, Liu GQ, Li Y: [A sample research on prevalence and risk factors of amnestic mild cognitive impairment in elderly in Shijiazhuang.]. Clinical Focus 2020, 35(07):610-615.

24. Xie Z, Lv X, Hu Y, Ma W, Xie H, Lin K, Yu X, Wang H: Development and validation of the geriatric depression inventory in Chinese culture. Int Psychogeriatr 2015, 27(9):1505-1511.

25. Tombaugh TN, Mclntyre NJ: The mini-mental state examination: a comprehensive review. J Am Geriatr Soc 1992, 40(9):922-935.

26. Morris JC: The Clinical Dementia Rating (CDR): current version and scoring rules. Neurology 1993, 43(11):2412-2414.

27. Guo Q-H, Sun YT, Yu PM, Hong Z, Lv CZ: Norm of auditory verbal learning test in the normal aged in Chinese community. Chin J Clin Psychol 2007, 15:132-135.

28. Chapman KR, Bing-Canar H, Alosco ML, Steinberg EG, Martin B, Chaisson C, Kowall N, Tripodis Y, Stern RA: Mini Mental State Examination and Logical Memory scores for entry into Alzheimer's disease trials. Alzheimers Res Ther 2016, 8:9.

29. Cheung RW, Cheung MC, Chan AS: Confrontation naming in Chinese patients with left, right or bilateral brain damage. J Int Neuropsychol Soc 2004, 10(1):46-53.

30. Reitan RM: The relation of the trail making test to organic brain damage. J Consult Psychol 1955, 19(5):393-394.

31. Buysse DJ, Reynolds CF, 3rd, Monk TH, Berman SR, Kupfer DJ: The Pittsburgh Sleep Quality Index: a new instrument for psychiatric practice and research. Psychiatry Res 1989, 28(2):193-213.

32. Zheng B, Li M, Wang KL, Lv J: Analysis of the reliability and validity of the Chinese version of Pittsburgh sleep quality index among medical college students. Beijing da xue xue bao Yi xue ban = Journal of Peking University Health sciences 2016, 48(3):424-428.

33. Goldman JG, Weis H, Stebbins G, Bernard B, Goetz CG: Clinical differences among mild cognitive impairment subtypes in Parkinson's disease. Mov Disord 2012, 27(9):1129-1136.

34. Petersen RC: Mild cognitive impairment as a diagnostic entity. J Intern Med 2004, 256(3):183-194.

35. Petersen RC, Smith GE, Waring SC, Ivnik RJ, Kokmen E, Tangelos EG: Aging, memory, and mild cognitive impairment. Int Psychogeriatr 1997, 9 Suppl 1:65-69.

36. Zhang M, Qu G, Jin H, Cai G, Wang Z: [Comparison of several dementia testing tools]. Chin J Neurol 1991, 24(4):194-196. 
37. Gavrila D, Antúnez C, Tormo MJ, Carles R, García Santos JM, Parrilla G, Fortuna L, Jiménez J, Salmerón D, Navarro C: Prevalence of dementia and cognitive impairment in Southeastern Spain: the Ariadna study. Acta Neurol Scand 2009, 120(5):300-307.

38. Katz MJ, Lipton RB, Hall CB, Zimmerman ME, Sanders AE, Verghese J, Dickson DW, Derby CA: Agespecific and sex-specific prevalence and incidence of mild cognitive impairment, dementia, and Alzheimer dementia in blacks and whites: a report from the Einstein Aging Study. Alzheimer Dis Assoc Disord 2012, 26(4):335-343.

39. Zhao Q, Lv Y, Zhou Y, Hong Z, Guo Q: Short-term delayed recall of auditory verbal learning test is equivalent to long-term delayed recall for identifying amnestic mild cognitive impairment. PLoS One 2012, 7(12):e51157.

40. De Simone MS, Perri R, Fadda L, Caltagirone C, Carlesimo GA: Predicting progression to Alzheimer's disease in subjects with amnestic mild cognitive impairment using performance on recall and recognition tests. J Neurol 2019, 266(1):102-111.

41. Fleisher AS, Sowell BB, Taylor C, Gamst AC, Petersen RC, Thal LJ, Alzheimer's Disease Cooperative S: Clinical predictors of progression to Alzheimer disease in amnestic mild cognitive impairment. Neurology 2007, 68(19):1588-1595.

42. Zhong Y, Huang L, Cai S, Zhang Y, von Deneen KM, Ren A, Ren J: Altered effective connectivity patterns of the default mode network in Alzheimer's disease: an fMRI study. Neurosci Lett 2014, 578:171-175.

43. Zhou Y, Dougherty JH, Jr., Hubner KF, Bai B, Cannon RL, Hutson RK: Abnormal connectivity in the posterior cingulate and hippocampus in early Alzheimer's disease and mild cognitive impairment. Alzheimers Dement 2008, 4(4):265-270.

44. Binnewijzend MA, Schoonheim MM, Sanz-Arigita E, Wink AM, van der Flier WM, Tolboom N, Adriaanse SM, Damoiseaux JS, Scheltens P, van Berckel BN et al: Resting-state fMRI changes in Alzheimer's disease and mild cognitive impairment. Neurobiol Aging 2012, 33(9):2018-2028.

45. Weiler M, Fukuda A, Massabki LH, Lopes TM, Franco AR, Damasceno BP, Cendes F, Balthazar ML: Default mode, executive function, and language functional connectivity networks are compromised in mild Alzheimer's disease. Curr Alzheimer Res 2014, 11(3):274-282.

46. Chan KY, Wang W, Wu JJ, Liu L, Theodoratou E, Car J, Middleton L, Russ TC, Deary IJ, Campbell H et al: Epidemiology of Alzheimer's disease and other forms of dementia in China, 1990-2010: a systematic review and analysis. Lancet 2013, 381(9882):2016-2023.

47. Alzheimer's Association. Alzheimer's disease facts and figures. Alzheimer's Dement.2020.https://doi.org/10.1002/alz.12068.

48. Sosa AL, Albanese E, Stephan BC, Dewey M, Acosta D, Ferri CP, Guerra M, Huang Y, Jacob KS, Jiménez-Velázquez IZ et al: Prevalence, distribution, and impact of mild cognitive impairment in Latin America, China, and India: a 10/66 population-based study. PLoS Med 2012, 9(2):e1001170.

49. Jang H, Ye BS, Woo S, Kim SW, Chin J, Choi SH, Jeong JH, Yoon SJ, Yoon B, Park KW et al: Prediction Model of Conversion to Dementia Risk in Subjects with Amnestic Mild Cognitive Impairment: A 
Longitudinal, Multi-Center Clinic-Based Study. J Alzheimers Dis 2017, 60(4):1579-1587.

50. De Ronchi D, Berardi D, Menchetti M, Ferrari G, Serretti A, Dalmonte E, Fratiglioni L: Occurrence of cognitive impairment and dementia after the age of 60: a population-based study from Northern Italy. Dement Geriatr Cogn Disord 2005, 19(2-3):97-105.

51. Dominguez J, Fe de Guzman M, Reandelar M, Thi Phung TK: Prevalence of Dementia and Associated Risk Factors: A Population-Based Study in the Philippines. J Alzheimers Dis 2018, 63(3):1065-1073.

52. Stern Y: Cognitive reserve in ageing and Alzheimer's disease. Lancet Neurol 2012, 11(11):1006-1012.

53. Bruce DG, Davis WA, Casey GP, Starkstein SE, Clarnette RM, Almeida OP, Davis TM: Predictors of cognitive decline in older individuals with diabetes. Diabetes Care 2008, 31(11):2103-2107.

54. Roberts RO, Knopman DS, Geda YE, Cha RH, Pankratz VS, Baertlein L, Boeve BF, Tangalos EG, Ivnik RJ, Mielke MM et al: Association of diabetes with amnestic and nonamnestic mild cognitive impairment. Alzheimers Dement 2014, 10(1):18-26.

55. Winkler A, Dlugaj M, Weimar C, Jöckel KH, Erbel R, Dragano N, Moebus S: Association of diabetes mellitus and mild cognitive impairment in middle-aged men and women. J Alzheimers Dis 2014, 42(4):1269-1277.

56. Ma L, Wang J, Li Y: Insulin resistance and cognitive dysfunction. Clin Chim Acta 2015, 444:18-23.

57. Ramasamy R, Vannucci SJ, Yan SS, Herold K, Yan SF, Schmidt AM: Advanced glycation end products and RAGE: a common thread in aging, diabetes, neurodegeneration, and inflammation. Glycobiology 2005, 15(7):16r-28r.

58. Reitz C, Tang MX, Manly J, Mayeux R, Luchsinger JA: Hypertension and the risk of mild cognitive impairment. Arch Neurol 2007, 64(12):1734-1740.

59. Tervo S, Kivipelto $M$, Hänninen $T$, Vanhanen $M$, Hallikainen M, Mannermaa A, Soininen H: Incidence and risk factors for mild cognitive impairment: a population-based three-year follow-up study of cognitively healthy elderly subjects. Dement Geriatr Cogn Disord 2004, 17(3):196-203.

60. Casado Naranjo I, Portilla Cuenca JC, Duque de San Juan B, García AF, Sevilla RR, Serrano Cabrera A, Hijón CC, Romero Chala S, Fuentes JM, Ramírez Moreno JM: Association of vascular factors and amnestic mild cognitive impairment: a comprehensive approach. J Alzheimers Dis 2015, 44(2):695704.

61. Cai TP, Chen M, Long JW, Zhou TT, Liu B, Wu L: [Study on the outcome of mild cognitive impairment to Alzheimer's disease in the elderly in Nanchang community.]. Chinese Journal of Disease Control \& Prevention 2020, 24(01):62-66.

62. Cavuoto MG, Kinsella GJ, Ong B, Pike KE, Nicholas CL: Naturalistic Measurement of Sleep in Older Adults with Amnestic Mild Cognitive Impairment: Anxiety Symptoms Do Not Explain Sleep Disturbance. Curr Alzheimer Res 2019, 16(3):233-242.

63. Hu M, Zhang P, Li C, Tan Y, Li G, Xu D, Chen L: Sleep disturbance in mild cognitive impairment: a systematic review of objective measures. Neurol Sci 2017, 38(8):1363-1371. 
64. Cavuoto MG, Ong B, Pike KE, Nicholas CL, Bei B, Kinsella GJ: Better Objective Sleep Quality in Older Adults with High Subjective Memory Decline. J Alzheimers Dis 2016, 53(3):943-953.

65. Cai S, Li T, Zhang L, Shi L, Liao J, Li W, Cheng G, Tan W, Rong S: Characteristics of Sleep Structure Assessed by Objective Measurements in Patients With Amnestic Mild Cognitive Impairment: A MetaAnalysis. Front Neurol 2020, 11:577126. 